\title{
Different forms of life satisfaction and their relation to affectivity
}

\author{
Claudia Harzer, Christian Ehrlich
}

\begin{abstract}
Aims: The present study is aimed at studying the research question whether high satisfaction levels achieved through either (1) the fact that one's quality of life is truly satisfactory (i.e., stabilized life satisfaction) or through (2) adapting a more favorable perception of one's quality of life by lowering standards (i.e., resigned life satisfaction) are associated with different levels of positive affect (PA) and negative affect (NA) when compared to each other but also when compared to dissatisfied individuals. Methods: A sample of 104 adults completed measures assessing stabilized and resigned life satisfaction, PA and NA, and global life satisfaction (i.e., no explicit consideration of differences in standards) in an online survey. Participants were not paid for participation but received feedback on results of the study if interest was expressed. Results: Stabilized life satisfaction and global life satisfaction showed highly similar correlation pattern with PA and NA. Resigned satisfaction was negatively associated with PA and positively correlated with NA. Stabilized and resigned satisfied individuals showed more favorable levels of PA and NA compared with
\end{abstract}

Claudia Harzer ${ }^{1}$, Christian Ehrlich ${ }^{2}$

Affiliations: ${ }^{1}$ Ph.D., Visiting Professor, Department of Psychology, University of Kassel, Germany; ${ }^{2} P h . D .$, Senior Lecturer, Department of Business and Management, Oxford Brookes University, Oxford, UK.

Corresponding Author: Claudia Harzer, University of Kassel, Department of Psychology, Hollaendische Str. 36-38, 34127 Kassel, Germany; Email: harzer.c@gmail.com

Received: 06 January 2016

Accepted: 19 February 2016

Published: 03 May 2016 dissatisfied individuals, but did not differ from each other with regard to their levels of PA and NA. Conclusion: Although showing a less favorable correlation pattern with $P A$ and NA, adopting a resigned form of satisfaction (i.e., taking a more favorable view of one's quality of life by lowering individual standards) seemed to prevent individuals from experiencing the same high levels of NA like dissatisfied ones. This has not been studied in detail so far, and therefore, the present paper opens a further area of research within the context of life satisfaction.

Keywords: Affectivity, Individual standards, Life satisfaction, Resigned satisfaction, Stabilized satisfaction

\section{How to cite this article}

Harzer C, Ehrlich C. Different forms of life satisfaction and their relation to affectivity. Edorium $\mathrm{J}$ Psychol 2016;2:8-13.

Article ID: $100008 \mathrm{P} 13 \mathrm{CH} 2 \mathrm{O} 16$

$* * * * * * * * *$

doi:10.5348/P13-2016-8-SR-2

\section{INTRODUCTION}

Life satisfaction measures are widely accepted as an indicator for people's quality of life [1]. However, they tend to be negatively skewed with average scores typically way above the neutral point of the scale used $[2,3]$. Acknowledging the plethora of research that identified a number of biases impacting on satisfaction scores [4], 
this paper argues that one important cognitive process, which leads to relatively high satisfaction scores, has, so far, been mainly overlooked. That is, people at times lower their standards with which they judge the quality of their life $[5,6]$ to perceive life in a more favorable way. Thus, one contributing factor to high satisfaction scores can be due to the fact that a proportion of individuals start to cognitively re-evaluate their life when their life does not meet their expectations in order to reduce cognitive dissonance, and subsequently perceive life in a more favorable way [7]. Against this backdrop, the question arises whether above average levels of satisfaction, either because (1) life is truly satisfactory or (2) because standards have been lowered, are associated differently with other important indicators of people's quality of life such as affective subjective well-being (SWB; i.e., positive and negative affect).

\section{Different forms of satisfaction}

Generally, life satisfaction refers to people's cognitive evaluation of their life, based on their own standards $[5,8]$. Individuals make a comparison between their perceived life circumstances and their unique set of standards with which they judge the quality of their life [9]. Standards are not externally imposed, but "each individual sets [them] for him or herself" [1; p. 71]. A discrepancy whereby the individual standards are higher or lower than the current conditions will result in various degrees of satisfaction or dissatisfaction. Such an understanding of the role of individual standards can in part be questioned; mainly because the level of individual standards is not considered to change the quality or nature of satisfaction as such.

In the light of this, we argue that individual standards can be on different levels and that the fulfillment of these different standards leads to different forms of satisfaction. Within the scope of the present paper, we distinguish between a stabilized and a resigned form of satisfaction $[10,11]$. Stabilized satisfaction is characterized by having maintained the original, genuine standards. Resigned satisfaction is "positively inflated" as it is characterized by lowered standards to make life appear more positive. Both forms of satisfaction are characterized by a fulfillment of individual standards as opposed to dissatisfied individuals who feel that life does not meet their standards.

\section{Aims and hypotheses}

The present study aims to investigate whether stabilized and resigned satisfaction are associated with different affective reactions to life. Those affective reactions of stabilized and resigned satisfied individuals are also compared to the affective reactions of dissatisfied individuals. More precisely, we hypothesize that (1) people who adopted a stabilized form of life satisfaction report higher levels of positive affect (PA) compared to people with a resigned form of life satisfaction. Mainly because, lowered standards reduce the chance of authentic accomplishments when standards are met. Nevertheless, those who adopted, (2) a resigned form of satisfaction meet their lowered standards and report higher levels of PA compared with dissatisfied individuals. (3) we also hypothesize that there are no differences regarding the reported level of negative affect (NA) between people who adopted a stabilized or resigned form of satisfaction, because in both causes not meeting one's standards, i.e. dissatisfaction, is prevented. Additionally, (4) people who adopted a stabilized or a resigned form of life satisfaction report lower levels of NA than dissatisfied individuals. Finally, as resigned and stabilized satisfied individuals have been found to slightly differ in their global satisfaction levels [11], global life satisfaction has been controlled for when testing these hypotheses.

\section{MATERIALS AND METHODS}

\section{Participants}

The sample consisted of 104 German-speaking adult volunteers (53 men, 51 women). Their mean age was 42.71 years $(\mathrm{SD}=10.49$; range $19-70$ years). Participants were highly educated (66 had a Master's degree, 6 a PhD degree; 28 had finished an apprenticeship; 3 finished school after 9 years of education, and 1 had a high school diploma). Most of the participants were married (51) or in a relationship (33); 14 were single, 5 were divorced, and 1 was widowed. Participants represented a wide array of occupations.

\section{Instruments}

For the purpose of the present study the stabilized and resigned life satisfaction scale (SRLSS) was compiled by adapting 16 items from Baumgartner and Udris's list of stabilized and resigned job satisfaction items to the life satisfaction context [12]. The 16 items, using a five-point answer format from $1=$ strongly disagree to $5=$ strongly agree, revealed sufficient reliability indices of $\alpha=0.89$ for stabilized ( $\alpha=0.91$ for females, $\alpha=0.86$ for males) and $\alpha=0.84$ for resigned satisfaction ( $\alpha=0.85$ for females, $\alpha$ $=0.82$ for males; see Table 1 for an overview of the items and their factor loadings) [13].

Affective SWB was measured using the Mood Survey [14], which includes 16 adjectives such as happy, depressed, vigorous, and unmotivated to measure positive affect (PA) and negative affect (NA). The adjectives have to be answered with respect to how often those affects have been experienced during the last couple of months ranging from $1=$ not at all to $7=$ very frequently. The mood survey showed satisfactory reliability and validity [14, 15]. The PA and the NA scales had internal consistencies of $\alpha=0.95$ ( $\alpha=0.96$ for females, $\alpha=0.91$ for males $)$ and $\alpha=0.93(\alpha=0.92$ for females, $\alpha=0.93$ for males $)$ in the present sample, respectively.

Global life satisfaction (i.e., cognitive SWB) was measured with the satisfaction with life scale (SWLS; 
[1]), which is a widely used five-item measure of life satisfaction utilizing a seven-point answer format (from 1 $=$ strongly disagree to $7=$ strongly agree). The SWLS does not consider any differences in standards [1]. The German version of the SWLS administered in the present study, showed satisfactory reliability and validity [16-19]. It revealed high internal consistency in the present sample ( $\alpha=0.87 ; \alpha=0.88$ for females, $\alpha=0.85$ for males).

\section{Procedure}

Participants were recruited in several ways to obtain a heterogeneous sample. For example, people were informed about the survey by press coverage (e.g., newspaper and magazine), by online advertisement (e.g., through a website offering information about psychological studies) as well as by snowball system via email and social networks. Participants completed the SRLSS, the SWLS, and the mood survey and provided information on demographics in an online survey after informed consent was given. Data collection took place between June and July 2012 as part of a wider project on quality of life. Participants were not paid for participation but received feedback on results of the study if interest was expressed.

\section{RESULTS}

\section{Descriptive analyses of the measures}

Descriptive statistics were computed for all the scales. Furthermore, correlation among the scales and between them and the demographic variables were examined (Table 2). The descriptive statistics reveal a general happy sample with regard to cognitive and affective SWB. The correlations among PA, NA, and SWLS were numerically higher than those found in other studies using similar measures but yielded a comparable pattern [9]. Despite the high intercorrelations between PA and NA, a principal component analysis still indicated that these two aspects of affective SWB could be separated.

Overall, stabilized life satisfaction and life satisfaction showed highly similar correlation pattern with positive and negative affect. Resigned satisfaction was negatively associated with PA and positively correlated with NA indicating that resigned satisfaction included aspects of dissatisfaction.

\section{Forms of life satisfaction and affect}

To examine whether stabilized and resigned satisfaction as well as dissatisfaction are associated with different levels of affect, participants were allocated

Table 1: Oblimin rotated two-factor solution (pattern matrix) for the stabilised and resigned life satisfaction scale (principal axis factor analysis)

\begin{tabular}{|c|c|c|}
\hline Items & 1 & 2 \\
\hline Life is exactly right for me. I am feeling really well. & 0.74 & -0.29 \\
\hline I am really satisfied with my life and wish everything stays the same in the near future. & 0.86 & 0.00 \\
\hline I am truly satisfied with my life. It meets my needs and wishes, and I would like it to stay like that. & 0.89 & 0.02 \\
\hline I wish that nothing changes in my life. & 0.66 & 0.08 \\
\hline I have reached my goals in life and I am satisfied with what I have achieved. & 0.45 & 0.13 \\
\hline I am satisfied, because I got what I expect from life. & 0.76 & -0.01 \\
\hline Hopefully my life always stays as good as it is now. I am really satisfied. & 0.85 & -0.08 \\
\hline One cannot make many demands with regard to having one's needs fulfilled in life. & 0.01 & 0.59 \\
\hline I am satisfied with my life - I tell myself, it could be much worse. & 0.17 & 0.62 \\
\hline Because I do not expect too much, I am quite satisfied with my life. & 0.09 & 0.48 \\
\hline $\begin{array}{l}\text { I am really satisfied with my life. My life does not really meet my needs and wishes, but it could be much } \\
\text { worse. }\end{array}$ & -0.07 & 0.75 \\
\hline I have not really reached my goals in life, but I settle with what I got so far. & 0.06 & $\mathbf{0 . 5 0}$ \\
\hline You cannot expect much in life. & -0.12 & 0.64 \\
\hline My life is not ideal, but it could be much worse. & -0.31 & 0.70 \\
\hline I have no choice but to accept the circumstances. & -0.26 & 0.64 \\
\hline Because my circumstances could be worse, I can be satisfied with life. & 0.17 & 0.60 \\
\hline
\end{tabular}

Note. Bold indicates highest factor loadings of the scales. Explained variance was $28.60 \%$ and $20.36 \%$ for factor 1 and 2 , respectively. Items were translated from German to English in a translation-back translation procedure, and the initial translation was created by committee approach [13]. 
Table 2: Descriptive Statistics and Correlations

\begin{tabular}{|c|c|c|c|c|c|c|c|c|c|c|c|c|c|}
\hline Variables & Min & Max & M & SD & $\mathbf{S}$ & $\mathbf{K}$ & 1 & 2 & 3 & 4 & 5 & 6 & 7 \\
\hline 1. Gender & 1 & 2 & -- & -- & -- & -- & & & & & & & \\
\hline 2. Age & 19 & 70 & 42.71 & 10.49 & -0.07 & -0.43 & -0.14 & & & & & & \\
\hline $\begin{array}{l}\text { 3. Marital } \\
\text { status }\end{array}$ & 1 & 2 & -- & -- & -- & -- & -0.11 & $0.27^{* *}$ & & & & & \\
\hline $\begin{array}{l}\text { 4. Stabilised } \\
\text { satisfaction } \\
\text { (SRLSS) }\end{array}$ & 1.00 & 4.71 & 3.12 & 0.81 & -0.57 & -0.23 & -0.15 & 0.05 & $0.20^{*}$ & & & & \\
\hline $\begin{array}{l}\text { 5. Resigned } \\
\text { satisfaction } \\
\text { (SRLSS) }\end{array}$ & 1.00 & 4.22 & 2.15 & 0.65 & 0.51 & -0.07 & 0.18 & 0.01 & -0.04 & -0.09 & & & \\
\hline $\begin{array}{l}\text { 6. Life } \\
\text { satisfaction } \\
\text { (SWLS) }\end{array}$ & 8.00 & 34.00 & 25.61 & $5 \cdot 35$ & -0.88 & 0.97 & -0.19 & 0.02 & $0.19^{*}$ & $0.75^{* * *}$ & $-0.35^{* * *}$ & & \\
\hline $\begin{array}{l}\text { 7. Positive } \\
\text { affect (PA) }\end{array}$ & 2.13 & 7.00 & $5 \cdot 35$ & 1.07 & -0.94 & 0.82 & -0.19 & -0.02 & 0.10 & $0.61^{* * *}$ & $-0.21^{*}$ & $0.71^{* * *}$ & \\
\hline $\begin{array}{l}\text { 8. Negative } \\
\text { affect (NA) }\end{array}$ & 1.00 & 6.38 & 2.75 & 1.19 & 1.07 & 0.75 & $0.38^{* * *}$ & -0.06 & -0.09 & $-0.53^{* * *}$ & $0.20^{*}$ & $-0.61^{* * *}$ & $-0.63^{* * *}$ \\
\hline
\end{tabular}

Note. $\mathrm{N}=104 . \mathrm{S}=$ Skewness; $\mathrm{K}=$ Kurtosis. Gender: 1 = male, 2 = female; Marital status: 1 = not in a romantic relationship ( $\mathrm{n}=\mathbf{2 0}$ ), 2 = living in a romantic relationship $(\mathrm{n}=84)$.

to one of these three categories using k-means cluster analysis [12] utilizing the 16 items of the SRLSS. Individuals allocated to group 1 reported low scores in both stabilized and resigned life satisfaction. The second group was the group with the highest scores in resigned life satisfaction, and the third group showed low scores in resigned life satisfaction and the highest scores in stabilized life satisfaction. The groups 1, 2, and 3 were therefore labeled as dissatisfied, resigned satisfied, and stabilized satisfied, respectively. To further test whether these clusters of individuals differed with respect to PA and NA, two ANCOVAs were computed with group membership as main factor (dissatisfied, resigned and stabilized). The PA and NA were the dependent variables. The control variables were age, gender, marital status, and life satisfaction (Stabilized and resigned satisfied participants did differ significantly from each other in global life satisfaction, $\mathrm{M}_{\text {Resigned satisfied }}=5.14$ vs. $\mathrm{M}_{\text {Stabilized }}$ satisfied $=5.71, \mathrm{p}=0.004$ ). Post hoc tests (Bonferroni) were computed for pairwise comparisons of group differences.

ANCOVAs indicated that group membership had an effect on PA $\left(\mathrm{F}[2,104]=6.04, \mathrm{p}<0.05\right.$, partial $\eta^{2}=$ $0.111)$, and on NA $\left(\mathrm{F}[2,104]=6.36, \mathrm{p}<0.01\right.$, partial $\eta^{2}=$ o.116). Post hoc tests revealed no significant differences between resigned and stabilized satisfied individuals in PA or NA. However, both resigned and stabilized satisfied individuals showed significant lower levels of NA, and significant higher levels of PA compared with dissatisfied individuals (Figure 1). Thus, the findings are in support of hypotheses 2, 3 and 4. Hypothesis 1 is rejected.

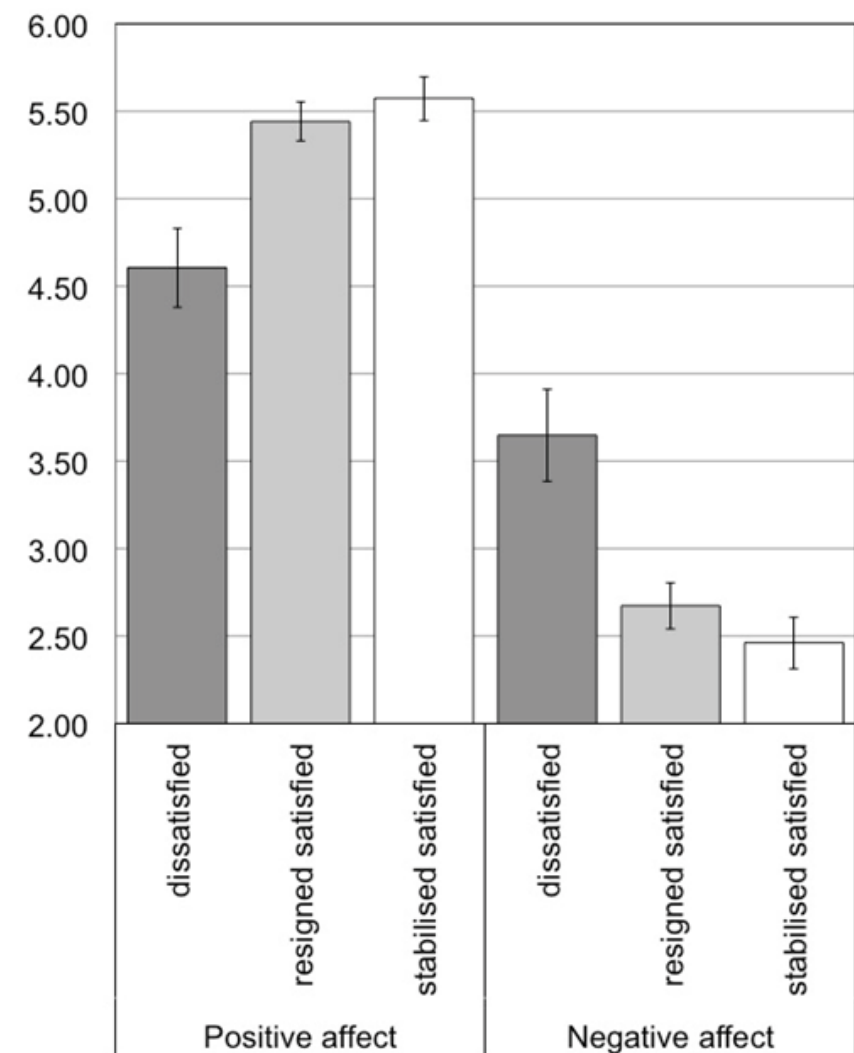

Figure 1: Means of the groups dissatisfied, resigned satisfied, and stabilized satisfied in positive affect and negative affect. Significance levels of post hoc tests (Bonferroni) for group differences between the dissatisfied and the other two groups in positive affect and negative affect were all $\mathrm{p}<0.01$. Significance levels of differences between resigned and stabilized satisfied were $\mathrm{p}>0.05$. 


\section{DISCUSSION}

The findings of this study highlight the importance of individual standards as a constituting element of life satisfaction. More precisely, the findings suggest that lowering standards is a beneficial way of keeping satisfaction levels moderately high with no significant differences in affective SWB when compared with stabilized individuals. Moreover, the benefits with regards to PA and NA compared with dissatisfied individuals are significant. With regard to the practical implications of these findings, it seems important to remember that the relatively high levels of satisfaction, through adapting a resigned form of satisfaction, come about through changes within the individual and are therefore not a true reflection of the (objective) quality of their life as such. This is in line with research that shows that life satisfaction levels are often unrelated to objective indicators of people's lives [4]. Assuming that the ability to perceive one's life in a more favorable way is limited and the notion that important life changes can lead to permanent drops in happiness [20], it seems important to monitor the proportion as well as the level of resignation within a certain population. Additionally, there is evidence that lowering one's expectation can be a successful strategy to avoid disappointment and therefore prevent the experience of low negative affect [21]. Further research is, therefore, needed to study when a change of standards is adaptive but equally at which point adapting a resigned form of satisfaction is a detrimental coping strategy. This latter is especially important in the light of correlational results presented here that indicated the resigned satisfaction goes along with lower levels of positive affect and higher levels of negative affect. The findings have to be treated with care because of the preliminary nature of the study. Particularly, because our measure for resigned and stabilized life satisfaction is simply an adapted version of items on job satisfaction and has only been tested rudimentary. This might in part be responsible for the insignificant differences in positive and negative affect between stabilized and resigned satisfaction although they were expected. Equally, our findings are based on a relatively small sample. Furthermore, sample was disproportionally highly educated and therefore, generalizability may be limited. Future research might develop a more advanced scale, which measures the level of satisfaction independently from the level of resignation which would overcome the currently given need to measure resigned satisfaction with items that include two contents (satisfaction levels and level of resignation), which does not fully comply with the rules for item construction. Furthermore, larger and more representative samples need to be studied to ensure statistical power and generalizability of results.

\section{CONCLUSION}

When studying life satisfaction it seems to be important to take a closer look at the level of standards. Scores from life satisfaction measures tend to be negatively skewed with average scores typically way above the neutral point of the scale used. This might be in part be explained by processes within individuals who cognitively re-evaluate their life to reduce cognitive dissonance when it does not meet their expectations, and subsequently perceive it in a more favorable way. Hence, the present paper opens a further area of research within the context of life satisfaction.

$$
* * * * * * * * *
$$

\section{Acknowledgements}

The preparation of this paper has been facilitated by a research grant of the Swiss National Science Foundation (SNSF; PBZHP1_147249) awarded to Claudia Harzer.

\section{Author Contributions}

Claudia Harzer - Substantial contributions to conception and design, Acquisition of data, Analysis and interpretation of data, Drafting the article, Revising it critically for important intellectual content, Final approval of the version to be published

Christian Ehrlich - Analysis and interpretation of data, Revising it critically for important intellectual content, Final approval of the version to be published

\section{Guarantor}

The corresponding author is the guarantor of submission.

\section{Conflict of Interest}

Authors declare no conflict of interest.

\section{Copyright}

(C) 2016 Claudia Harzer et al. This article is distributed under the terms of Creative Commons Attribution License which permits unrestricted use, distribution and reproduction in any medium provided the original author(s) and original publisher are properly credited. Please see the copyright policy on the journal website for more information.

\section{REFERENCES}

1. Diener E, Emmons RA, Larsen RJ, Griffin S. The Satisfaction With Life Scale. J Pers Assess 1985 Feb;49(1):71-5.

2. Blais MR, Vallerand RJ, Pelletier LG, Briere NM. The satisfaction scale: Canadian-French validationof the Satisfaction with Life Scale. [in French with English abstract]. Can J Behav Sci 1989 Apr;21(2):210-23.

3. Pavot W, Diener E. The Satisfaction with Life Scale and the emerging construct of life satisfaction. J Posit Psychol 2008;3(2):137-52. 
4. Schimmack U, Diener E, Oishi S. Life-satisfaction is a momentary judgment and a stable personality characteristic: the use of chronically accessible and stable sources. J Pers 2002 Jun;70(3):345-84.

5. Diener E, Inglehart R, Tay L. Theory and validity of life satisfaction scales. Soc Indic Res 2013;112:(3)497527.

6. Michalos AC. Multiple Discrepancies Theory (MDT). Soc Indic Res 1985;16(4):347-413.

7. Festinger L. A theory of cognitive dissonance. Evanston, IL: Row Peterson; 1957.

8. Weber M, Harzer C, Huebner ES, Hills KJ. Measures of life satisfaction across the lifespan. In: Boyle GJ, Saklofske DH, Matthews G eds. Measures of personality and social psychological constructs. 3ed. New York, NY: Academic Press; 2015. p. 101-30.

9. Pavot W, Diener E. Review of the Satisfaction with Life Scale. Psychol Assess 1993;5(2):164-72.

10. Bruggemann A. The differentiation of different forms of Work Satisfaction. [In German]. Arbeit und Leistung 1974;28:281-4.

11. Ziegler R, Schlett C. Forms of job satisfaction: Studies on the validity of the self-classification method and on differences in job valence, job situation, and dispositional affectivity. [In German with English abstract]. Zeitschrift für Arbeits- und Organisationspsychologie 2013;57:51-76.

12. Baumgartner C, Udris I. The Zurich model of work satisfaction -30 years still going strong. [In German]. In: Fischer L ed. Work satisfaction. Concepts and empirical findings. Goettingen, Germany: Hogrefe; 2005. p. 111-34.

13. Butcher JM, Pancheri P. A handbook of cross-national MMPI research. Minneapolis, MN: University of Minnesota Press; 1976.

14. Brunstein JC, Lautenschlager U, Nawroth B, Poehlmann K, Schultheiss O. Personal concerns, social motives, and emotional well-being. [In German with English abstract]. J Individ Differ 1995;16:1-10.

15. Abele-Brehm A, Brehm W. The conceptualization and measurement of mood: The development of the "Mood Survey". [In German with English abstract]. Diagnostica 1986;32:209-28.

16. Glaesmer H, Grande G, Braehler E, Roth M. The German version of the satisfaction with life scale (SWLS): psychometric properties, validity, and population-based norms. European Journal of Psychological Assessment 2011;27:127-32.

17. Ruch W, Harzer C, Proyer RT, Park N, Peterson C. Ways to happiness in German-speaking countries: The adaptation of the German version of the orientations to happiness questionnaire in paperpencil and internet samples. Eur J Psychol Assess 2010;26(3):224-31.

18. Ruch W, Proyer RT, Harzer C, Park N, Peterson C, Seligman, MEP. Values in Action Inventory of Strengths (VIA-IS): Adaptation and validation of the German version and the development of a peer-rating form. J Individ Dif 2010;31(3):138-49.

19. Ruch W, Proyer RT, Weber M. Humor as character strength among the elderly: Empirical findings on agerelated changes and its contribution to satisfaction with life. Z Gerontol Geriatr 2010;43(1):13-18.

20. Diener E, Lucas RE, Scollon CN. Beyond the hedonic treadmill: revising the adaptation theory of wellbeing. Am Psychol 2006 May-Jun;61(4):305-14.

21. Van Dijk WW, Zeelenberg M, Van der Pligt J. Blessed is they who expect nothing: Lowering expectations as a way of avoiding disappointment. J Econ Psychol 2003;24(4):505-16.
Access full text article on other devices

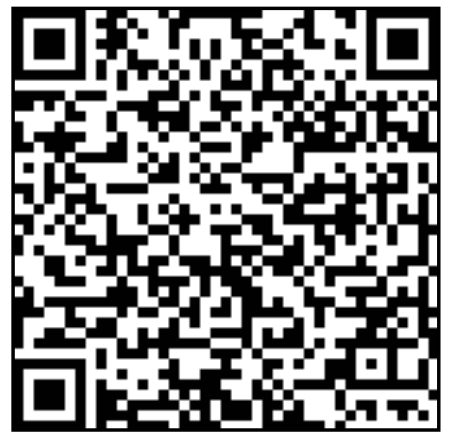

Access PDF of article on other devices

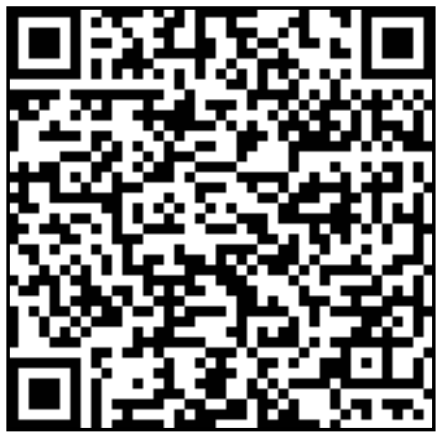

